\title{
Editorial
}

This issue of Aotearoa New Zealand Social Work provides an interesting selection of topics and research methods. All the studies were conducted primarily in Aotearoa New Zealand and utilise qualitative and quantitative methods, mixed methods and archival research. The topics demonstrate a wide span of social work concerns: parents of adult children with complex needs, children and young people, Pacific health, cultural support workers in health settings and the long-standing and vexed problem of accessing quality field placements for social work students. The books reviewed in the issue address vulnerability and marginality in human services, integrated health care, and social work practice in health care. The classic book review is a discursive re-examination of a 1979 sociological work, where the reviewer finds much of relevance to child and family policy today.

What this breadth of coverage reminds us is that social work, and indeed social services, is a very broad field of professional endeavour. While child protection is a significant part of social work, it often has disproportionate attention and thus influence on government discourse and policy. Members of the public might be surprised, for example, when they hear that Oranga Tamariki employs less than $25 \%$ of registered social workers. Social workers in health, justice, schools, community, disability and mental health make considerable contributions to Aotearoa New Zealand society and should be included in decisions about social work and social work education. Practitioners and researchers from these other fields are making a strong contribution to the journal. While all research is valuable, one often ignored function of social work research and scholarship, is to bring marginalised and less visible fields of practice to the fore. Several of the articles in this issue contribute to that foregrounding.
We hope to see more contributions from health, mental health and disability services in future issues.

Hemant Thakkar reports on a qualitative study conducted in Aotearoa New Zealand and India. In "It's like me leaving a manual of me behind", parents' perspectives about succession planning of long-term care and support for their disabled adult children with high and complex needs are explored. Six key components of succession planning were identified: preparing the child; preparing the informal network; sorting out the living arrangements; securing their financial future; creating a life plan and a training manual; and preparing the community. This qualitative study revealed that not all parents have the necessary skills and resources to engage in succession planning and hence it becomes crucial that social workers and other professionals working in social services provide appropriate support to these parents.

Kathryn Hay explores stakeholder perspectives on the growing concern about the availability of quality learning opportunities for students in "There is competition": Facing the reality of field education in Aotearoa New Zealand. Focus groups and interviews were conducted with tertiary educators and social work students from three Aotearoa New Zealand tertiary institutions. The sector is experiencing considerable pressure on placements due to competition, limited placement opportunities in some locations, high workloads, funding pressures, placement fatigue, and limited space and physical resources. These findings suggest that a comprehensive, sectorwide examination of the social work field education is needed.

The Strengths and Difficulties Questionnaire (SDQ) is an internationally recognised psychometric and behavioural screening tool. The Ministry of Social
AOTEAROA

NEW ZEALAND SOCIAL WORK 30(2), 1-2. 
Development in Aotearoa New Zealand has endorsed this tool as the primary behavioural screening and client outcome evaluation tool for the Social Workers in Schools service in 2018. Emma O'Neill reports on a quantitative study which explored two years of aggregated SDQ scores, compiled by youth workers in secondary schools, to understand what client outcomes could be evidenced. The findings suggest that the SDQ as a standalone behavioural screening and outcome evaluation tool within social work is limited. O'Neill argues that the use of SDQ in social work requires further examination to test its ability to communicate a client's level of need and intervention outcomes.

Archival research is the method used alongside qualitative interviews in Barbara Staniforth's article "The Auckland MA Sociology (Option II - Social Welfare and Development): A social work qualification gone but not forgotten". Over the period 1975-1979 the University of Auckland MA in Sociology (Option II-Social Welfare and Development) was offered as a qualifying social work programme. Staniforth conducted semi-structured interviews with staff and students who had been involved with this programme. Information was also obtained through exploring archived University documents, reports, and various forms of personal correspondence provided by June Kendrick. There were resource limitations and philosophical tensions within the Department about the qualification. There was little support for its continuation at the end of a three-year grant and after the departure of its main champion. Staniforth notes the contribution of the programme to the profession of social work in Aotearoa New Zealand.

\section{Editorial Collective}

August 2018
Margaret Pack reports on an exploratory mixed methods study which was a component of a larger evaluation of the primary health care strategy (PHCS) in Aotearoa New Zealand. The aim of the qualitative phase of the research was to explore the extent of use and satisfaction about service provision and delivery with the PHCS through the operation of Pacificled Primary Health Organisations (PHOs). The study was conducted using a case study design and in-depth interviews with service managers and health providers at six Pacificled PHOs. The study reveals tension between the business model, government reporting requirements, and the more altruistic values of those at the front line. Increased uptake of services was attributed to wrap-around, holistic, accessible services delivered by culturally responsive health providers who "go the extra mile" for their service users. Pack discusses the implications for health social work.

In another health context, this issue's research brief by Maree Goh reports on a small qualitative study of cultural support workers in Aotearoa New Zealand in "Exploring the role of cultural support workers in the New Zealand healthcare setting". Goh notes that as Aotearoa New Zealand becomes increasingly ethnically and linguistically diverse, the use of cultural support workers will become a much greater integral part of healthcare services. However, very little is currently known about the needs of these workers - the challenges of the role; their needs for appropriate training, support and supervision; and, how these can be met. Goh identifies significant challenges for the role but is optimistic about their ability to make a positive difference within the healthcare setting. 